\title{
Low-cost assessment of a stove improvement program in Peru
}

\author{
Boris Reiss*1, Isaac Jogues Roa ${ }^{1}$, Raleigh Bacharach ${ }^{3}$, Igor Burstyn ${ }^{2}$, Eyal Oren ${ }^{3}$ \\ 1: University of Arizona \\ 2: Drexel University \\ 3: San Diego State University \\ *correspondence to: boris.reiss@gmail.com
}

Authors declare no conflicts of interest.

Funding: No funding agency to report

\begin{abstract}
Background: Approximately 3 billion people worldwide, including more than 20 million people in Peru alone, depend on biomass fuels (BMF) for heating and boiling water, cooking, and lighting their homes. Burning BMF on poorly ventilated stoves results in household air pollution (HAP), which includes carbon monoxide (CO). Stove improvement programs aim to reduce indoor air pollution and are included in various organizations' education visits to Peru. The programs do not allow sufficient time, or provide equipment or skills training to determine if the stove improvements have been successful.
\end{abstract}

Objective: To develop and implement a rapid, low-cost method to measure CO concentrations in rural Peruvian households in order to assess the success of stove improvements.

Methods: CO concentrations were measured 159 times in 14 households (with 7 clean, 6 traditional, and 1 gas stove) near Cusco, Peru. CO concentrations were measured in one-minute intervals with MSA Altair $4 X$ multigas monitors. The likelihood of the $95^{\text {th }}$ percentile exceeding the NIOSH CO ceiling limit of $200 \mathrm{ppm}$ for each stove type was calculated.

Results: The probability of overexposure was almost three times lower with "clean" stoves than with traditional stoves, i.e., $24 \%$ vs $9 \%$.

Conclusion: A promising and pragmatic method to evaluate the increased effectiveness of clean stoves over traditional ones was developed and tested. This method supports the implementation of clean stoves as a risk reduction measure. 


\section{Introduction}

Approximately 3 billion people worldwide depend on biomass fuels (BMF) in order to heat and boil water, to cook, and to light their homes (Bonjour Sophie et al., 2013; WHO, 2006). Burning BMF on poorly ventilated stoves results in household air pollution (HAP), including particulate matter (PM), carbon monoxide (CO) and nitrogen dioxide $\left(\mathrm{NO}_{2}\right.$ ) (Jary et al., 2014; Perez-Padilla et al., 2010; Sota et al., 2014). Peru has a population of about 32 million (Central Intelligence Agency, 2019), among whom approximately 6.4 million lack modern-day energy sources for domestic purposes. Ninety-three percent (93\%) of Peruvians living in rural areas rely on BMF for heating water, cooking, and household lighting (Calzada \& Sanz, 2018; Central Intelligence Agency, 2019; INEI, 2007).

Figure 1 shows examples of traditional and the newer "clean" Peruvian stoves. Clean stoves have been developed in an effort to reduce emissions that contribute to HAP (Perez-Padilla et al., 2010; Quansah et al., 2017). Performance of these newer stoves depends on their design, proper installation and maintenance (Hartinger, Commodore, Hattendorf, Lanata, Gil, Verastegui, Aguilar-Villalobos, et al., 2013; Naeher et al., 2000).

$\mathrm{CO}$ and PM are commonly measured to estimate the HAP reduction provided by clean stoves (Bruce et al., 2004; Hartinger, Commodore, Hattendorf, Lanata, Gil, Verastegui, Aguilar-Villalobos, et al., 2013; Naeher et al., 2000; Pilishvili et al., 2016; Sharma \& Jain, 2019). For example, in rural Guatemala, a 24-hour arithmetic mean (AM) of 12.4 ppm CO was reported for traditional stoves, while the 24-hour AM for clean stoves was found to be 4.9 ppm (Bruce et al., 2004). Another study of CO in rural Guatemala found an AM of 5.9 ppm for traditional stoves and an AM of $1.3 \mathrm{ppm}$ for clean stoves, over a 22-hour period (Naeher et al., 2000). Similar findings regarding $\mathrm{CO}$ reductions were also found in a study conducted in Peru, where traditional stoves had an $\mathrm{AM}$ value of $3.14 \mathrm{ppm}$ while clean stoves had an AM value of $1.6 \mathrm{ppm}$ (Fitzgerald et al., 2012). On the other hand, in rural Peru, 48-hour indoor air concentrations of $\mathrm{CO}$ were reported to be similar between traditional and clean stoves (AM 5.8 vs 4.7 ppm) (Hartinger et al., 2013). The limitation of the above assessments lies in their time-consuming nature and reliance on expensive equipment, making it difficult to evaluate the stove on a large scale and in a timely manner.

The objective of this study was to develop and implement a rapid, low-cost method to assess indoor CO concentrations in rural Peruvian households where stove improvement programs had been implemented.

Figure 1 Examples of traditional and clean stoves

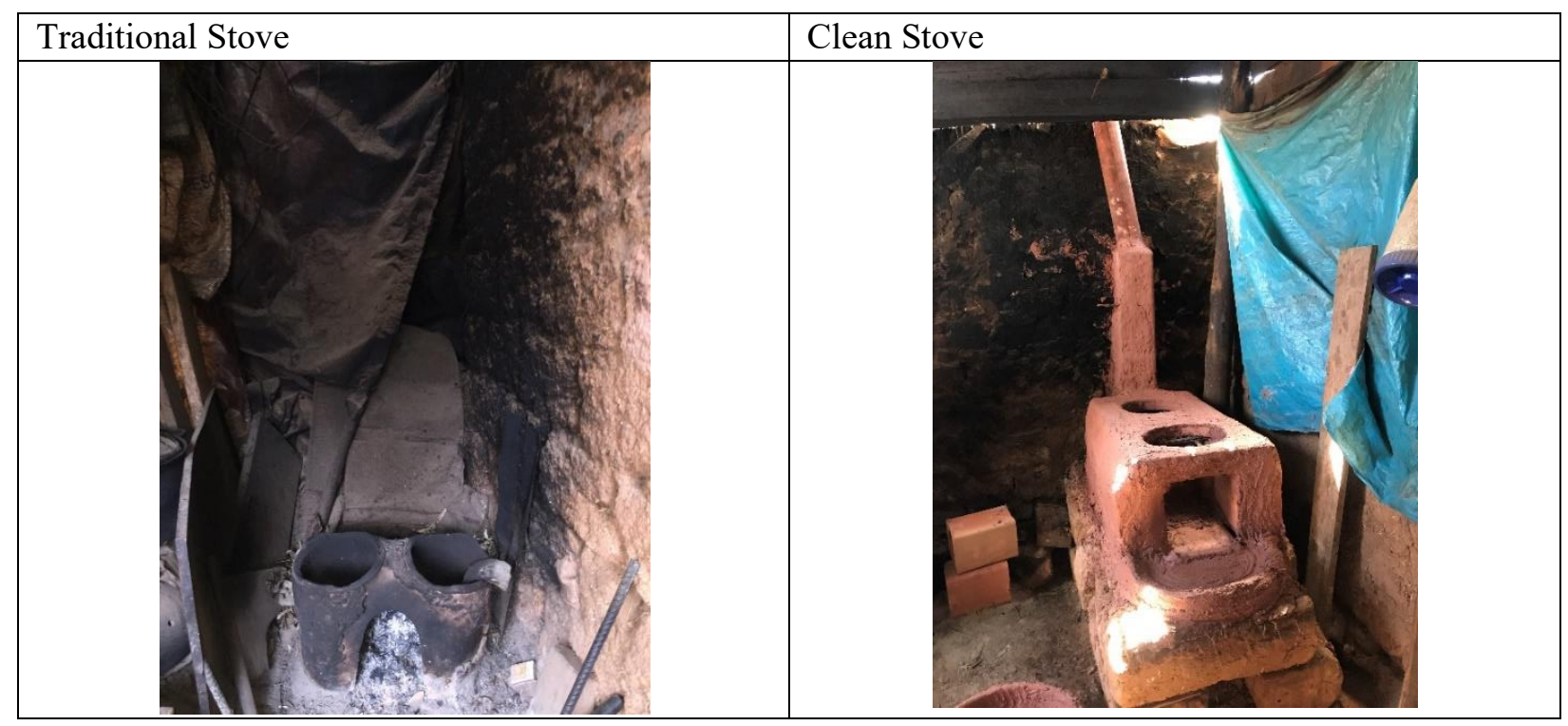




\section{Methods}

\section{Sampling strategy}

The sampling was integrated with the visit of a global health class. Students from multiple United States universities visit villages near the city of Cusco, Peru on monthly intervals. They often modify or upgrade household stoves during these visits. The students typically do not have the time, equipment, or skills to determine the success of the upgrade. For the purpose of this research, the instructor in one such class added a measurement day to their visit. Student groups were asked to sample in households with traditional and clean stoves. They were instructed to take measurements indoors, near each stove, and outside the home, in an approximately even number of traditional and clean stove households. Repeated one-minute measurements were taken. Students could minimize their presence in the homes in this way because it has been found in other settings, that peak measurements are associated with average concentrations (Preller, 2004).

\section{Data collection}

On June 27, 2019, four groups of students from San Diego State University's Global Health Study Abroad program collected the measurements. The households had been selected in advance by the program partner's non-governmental volunteer organization ProPeru. Four MSA Altair $4 X$ multigas monitors were used to collect the data. $\mathrm{CO}$ concentrations were measured five times in one-minute intervals inside the household and in ambient air directly outside the home. Students recorded the household location, number of people in the household, location of stove (indoor or outdoor), stove distance from the entrance door, time since stove was last used, estimated room volume, number of windows, chimney type, fuel type, and ongoing tasks on "field forms".

The monitors were calibrated at the University of Arizona at the beginning of the study with CO-free laboratory air (zero gas) and $100 \mathrm{ppm}$ CO in a gas mixture of $80 \%$ nitrogen and $20 \%$ oxygen (span gas). Zero and span gasses were measured with the MSA Altair 4Xs again immediately after all the instruments had been calibrated (as-left) and when all the instruments were returned from Peru (as-found). The calibrated monitors were shipped with a personal courier to and from Cusco, Peru. MSA's reported limit of detection (LOD) of 1 ppm was used in the analysis.

Data from the field forms were transferred into two Google Sheets spreadsheets (gsheet). The measurement date, stove, room volume, device serial numbers, and student measurement team identifier, for each set of measurements, were recorded on the first gsheet; the measured $\mathrm{CO}$ data and its descriptors, on the second. The data from the gsheets were imported into $R$ statistical software version 3.6.1 (R Core Team, 2019). The "join" function in the $R$ plyr package (version 1.8.3) (Wickham, 2020) was used to connect the two spread sheets (Wickham, 2011).

Data content of the variables: Stove Type, Task, Location, Usage-Status, and Ventilation Status were concatenated to create one aggregated variable to define unique exposure scenarios. This process was repeated for each record. One example: The concatenated value "Traditional-Outdoor-Cooking-Active-NoVntltn" defines the exposure scenario for a traditional stove, outside of the building, where the stove was in use and there was no ventilation system was attached to the it.

\section{Ethics}

Study participation was voluntary, and no personal data on residents were collected. The protocol was judged not to require an ethics assessment by the institutional review boards of the San Diego State University.

\section{Data Analysis}

Data were prepared for analysis and described using $R$ software (R Core Team, 2019). Examination of the normal probability plots revealed that the $\mathrm{CO}$ data were lognormally distributed (see Appendix). $\mathrm{CO}$ measurements that were below the MSA Altair $4 X$ multigas LOD of one part per million (1 ppm) (Mine Safety Appliances Company, 2017) were replaced with LOD $/ \sqrt{2}$ (Hornung \& Reed, 1990). 
The likelihood of exposure above the ceiling limit for CO (200 ppm) within each stove type was computed using Expostats (Expostats Version 1.0, Jerome Lavoué, Montréal, Canada). Expostats Tool 3 was used to compare the $\mathrm{CO}$ distributions associated with the categories: stove type, stove location, task, stove usage status, and ventilation direction (Lavoué et al., 2019). Expostats was also used to determine the following exposure probabilities: less than 1\% of the OEL, 1 to $10 \%$ of the OEL, 10 to $50 \%$ of the OEL, 50 to $100 \%$ of the OEL, and above the OEL. These exposure probabilities were assessed by stove type, task type, and aggregated scenarios.

The 200 ppm National Institute for Occupational Safety and Health (NIOSH) recommended ceiling limit for CO was used as the OEL in Expostats for the generation of overexposure probabilities. The Ceiling Limit is defined as the concentration of an airborne contaminant that should not be exceeded at any time (NIOSH 2007). The use of this limit is based on the understanding that cooking on stoves is part of the work performed in the households, even as it is recognized that such standards are too high for application in non-occupational settings (where children, the elderly, and persons too ill to work in conventional employment may be exposed). 


\section{Results}

The four-gas monitors measured, on average, an as-left CO concentration of $100 \pm 2.8 \mathrm{ppm}$ and an as-found $\mathrm{CO}$ concentration of $102.5 \pm 1.7 \mathrm{ppm}$, at $100 \mathrm{ppm} \mathrm{CO}$.

CO concentrations were measured 159 times at 14 houses and 14 stoves. Seven houses had clean stoves; six, traditional stoves; and one, a gas stove. Eleven different exposure scenarios, including measurements of ambient air, were observed. There was no evidence of systematic variability in exposure between households. Each CO measurement can be treated as independent. The between-household variance of $\log (\mathrm{CO})$ was 0.006 with standard error (SE) of 0.01, while within-household variance was $2.3(\mathrm{SE}=0.3)$ The analysis of random effects Analysis of variance (ANOVA) is not shown in detail.

Table 1 shows a summary of CO concentrations by type of stove. The average CO concentration measured with the traditional stoves was $21 \mathrm{ppm}$, almost three times that seen with clean stoves ( $8 \mathrm{ppm})$. The difference in geometric mean (GM) concentration was likewise on the order of two-fold: 6.9 ppm versus 2.6 ppm. The highest $\mathrm{CO}$ concentration $(120 \mathrm{ppm})$ was measured at a traditional stove. Measurements with traditional stoves were more variable, with geometric standard deviations (GSDs) of about 6 with traditional vs 5 with clean stoves. Ambient $\mathrm{CO}$ concentrations were far lower than those measured indoors and were relatively invariable.

Table 1: Summary of one-minute CO measurements at stoves and in ambient air

\begin{tabular}{lccccccc}
\hline Stove Type & $\mathbf{K}$ & $\mathbf{N}$ & $\mathbf{N}<\mathbf{L O D}$ & $\begin{array}{c}\text { AM } \\
(\mathbf{p p m})\end{array}$ & $\begin{array}{c}\text { ASD } \\
(\mathbf{p p m})\end{array}$ & $\begin{array}{c}\text { GM } \\
(\mathbf{p p m})\end{array}$ & $\mathbf{G S D}$ \\
\hline Clean & 7 & 48 & 28 & 8.4 & 12.0 & 2.6 & 5.0 \\
Gas & 1 & 5 & 5 & 0.7 & 0.0 & 0.7 & 1.0 \\
Traditional & 6 & 39 & 11 & 20.9 & 28.1 & 6.9 & 5.7 \\
Ambient air & 14 & 67 & 66 & 0.7 & 0.2 & 0.7 & 1.1 \\
\hline
\end{tabular}

K: Number of stoves; N: Number of samples per stove; AM: Arithmetic Mean; ASD: Arithmetic Standard Deviation; GM: Geometric Mean; GSD: Geometric Standard Deviation

Table 2 presents $\mathrm{CO}$ concentration by task. Burning the fuel (stoking the fire) and lighting were associated with the highest $\mathrm{CO}$ concentrations (GM about 8 to $9 \mathrm{ppm}$ ), while cooking was associated with the lowest concentration (GM 3 ppm). No active task was recorded at the gas stove.

Table 2: Summary of one-minute CO measurements associated with specific tasks and in ambient air

\begin{tabular}{lccccccc}
\hline Task & $\mathbf{K}$ & $\mathbf{N}$ & $\mathbf{N}<\mathbf{L O D}$ & $\begin{array}{c}\text { AM } \\
(\mathbf{p p m})\end{array}$ & $\begin{array}{c}\text { ASD } \\
(\mathbf{p p m})\end{array}$ & $\begin{array}{c}\text { GM } \\
(\mathbf{p p m})\end{array}$ & $\mathbf{G S D}$ \\
\hline Ambient air & 14 & 67 & 66 & 0.7 & 0.2 & 0.7 & 1.1 \\
Burning & 1 & 5 & 1 & 16.1 & 14.9 & 8.7 & 4.7 \\
Cooking & 9 & 49 & 28 & 14.6 & 26.5 & 2.9 & 6.2 \\
Lighting & 3 & 23 & 5 & 14.1 & 12.7 & 7.5 & 4.1 \\
NA & 3 & 15 & 10 & 7.1 & 11.8 & 1.9 & 4.8 \\
\hline
\end{tabular}

K: Number of stoves; N: Number of samples per stove; AM: Arithmetic Mean; ASD: Arithmetic Standard Deviation; GM: Geometric Mean; GSD: Geometric Standard Deviation; NA: no tasks recorded 
Table 3 shows average $\mathrm{CO}$ concentrations for each exposure scenario. For the preparation of food, four houses used a clean cookstove that vented outside of the house; two, a traditional stove indoors without ventilation; and two, a traditional stove outdoors without ventilation. The $\mathrm{CO}$ concentrations measured near the indoor, unvented traditional stoves, while a family member cooked, were on average $27 \mathrm{ppm}$. The average CO concentrations measured near the indoor, ventilated clean stoves during cooking were $1 \mathrm{ppm}$. The arithmetic means of the $\mathrm{CO}$ concentrations were similar for indoor, ventilated clean stoves while lighting the fuel and burning (stoking) the fire and ranged from about $16 \mathrm{ppm}$ to $17 \mathrm{ppm}$, respectively.

Table 3: Summary of one-minute CO measurements by exposure scenario

\begin{tabular}{lccccccc}
\hline Exposure scenario & $\mathbf{K}$ & $\mathbf{N}$ & $\begin{array}{c}\mathbf{N}< \\
\mathbf{L O D}\end{array}$ & $\begin{array}{c}\text { AM } \\
(\mathbf{p p m})\end{array}$ & $\begin{array}{c}\text { ASD } \\
(\mathbf{p p m})\end{array}$ & $\begin{array}{c}\text { GM } \\
(\mathbf{p p m})\end{array}$ & GSD \\
\hline Indoor stove location & & & & & & & \\
$\quad$ Clean- Burning-Active-VentedOtsd & 1 & 5 & 1 & 16.1 & 14.9 & 8.7 & 4.7 \\
Clean- Cooking-Active-VentedOtsd & 4 & 20 & 19 & 1.0 & 1.2 & 0.8 & 1.6 \\
Clean- Lighting-Active-VentedOtsd & 2 & 18 & 3 & 16.7 & 13.1 & 10.0 & 3.8 \\
Clean- NA-Pre-not-active-VentedOtsd & 1 & 5 & 5 & 0.7 & 0 & 0.7 & 1.0 \\
Gas- NA-Pre-not-active-NA & 1 & 5 & 5 & 0.7 & 0 & 0.7 & 1.0 \\
Traditional-Cooking-Active-NoVntltn & 2 & 10 & 5 & 27.1 & 38.0 & 5.6 & 9.3 \\
Traditional- Cooking-Post-not-active-NoVntltn & 2 & 7 & 3 & 5.3 & 6.7 & 2.4 & 3.9 \\
Traditional-Lighting-Post-not-active-NoVntltn & 1 & 5 & 2 & 4.5 & 4.0 & 2.7 & 3.5 \\
$\quad$ Traditional -NA-NA-NoVntltn & 1 & 5 & 0 & 19.8 & 13.6 & 13.9 & 3.1 \\
Outdoor stove location & & & & & & & \\
$\quad$ Traditional-Outdoor-Cooking-Active-NoVntltn & 2 & 12 & 1 & 32.3 & 31.5 & 17.0 & 4.1 \\
\hline
\end{tabular}

Notes: Format for exposure status variable: ‘Stove Type-Task-Usage Status-Ventilation Status'; NoVntltn: No ventilation of stove; VentedOtsd: Stove vented to the outside.

K: Number of stoves; N: Number of measurements; AM: Arithmetic Mean; ASD: Arithmetic Standard Deviation; GM: Geometric Mean; GSD: Geometric Standard Deviation

Figure 2 shows the $\mathrm{CO}$ exposure risk bands for each stove type. Ambient air is included in the risk bands as a reference. The lowest probability of exposure above the $200 \mathrm{ppm}$ OEL over a 5 minute period occurred in ambient air; all of probability is in the "<1\% of OEL" band ( $0 \%)$. The probability of overexposure dropped from $24 \%$ with traditional stoves to $9 \%$ for clean stoves.

Figure 3 shows the $\mathrm{CO}$ exposure risk bands for each stove use scenario. The probability of overexposure while cooking indoors ranged from $40 \%$ for the unventilated traditional stoves to $1 \%$ for ventilated clean stoves.

The probabilities of exceeding the OEL during the tasks of lighting fuel and burning versus stoking the fire are $9 \%$ and $21 \%$, respectively. 
Figure 2: Risk bands for 1-minute CO measurements relative to the 200 ppm NIOSH Ceiling limit for different types of stoves and ambient air.

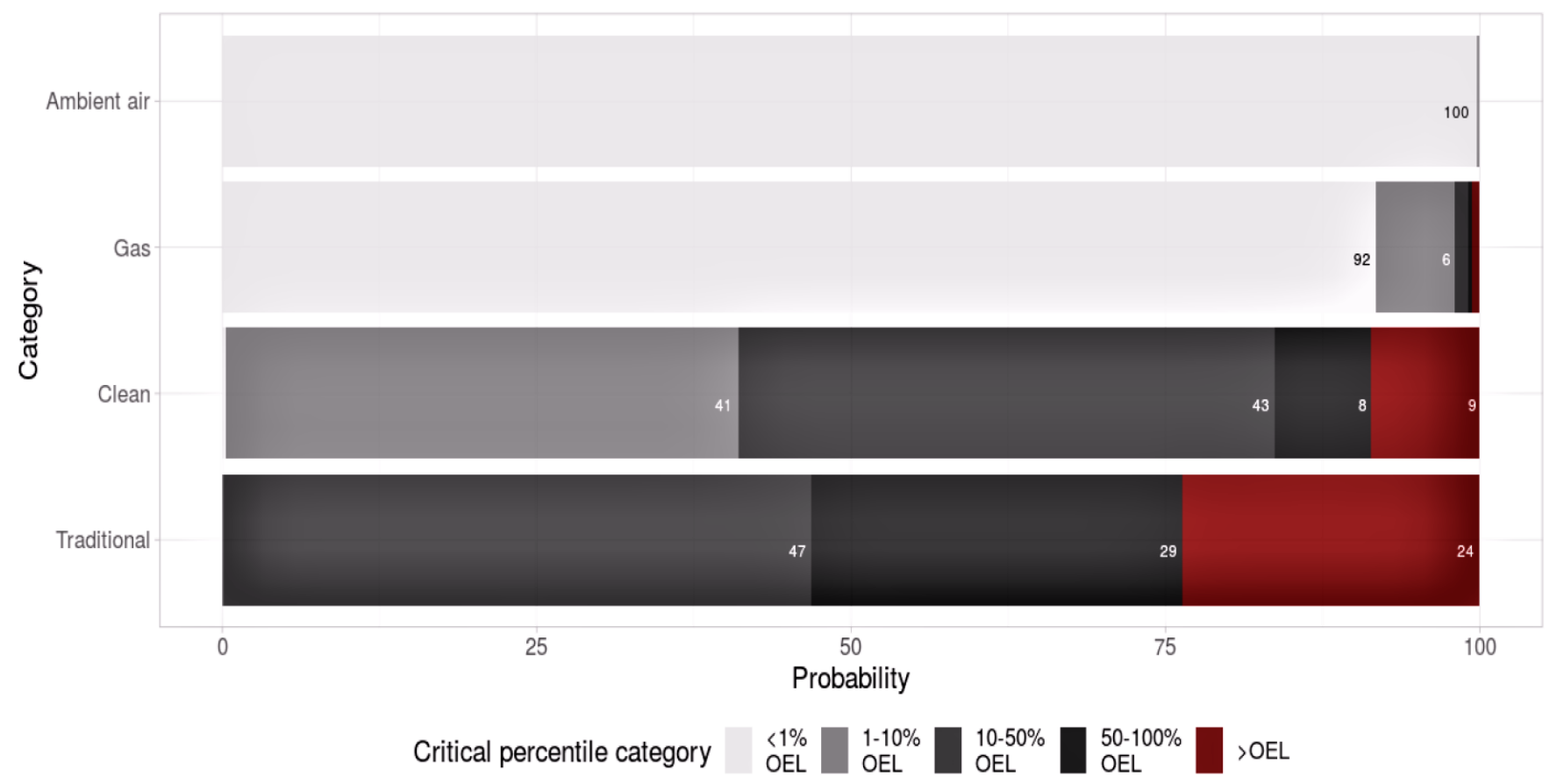

Figure 3: Risk bands for 1-minute CO measurements relative to the 200 ppm NIOSH Ceiling limit for different scenarios of stove use and ambient air






\section{Discussion}

The clean stoves consistently produced lower CO concentrations than the traditional stoves. For example, about 1 in 10 of the clean stoves can be classified as "poorly controlled" by the American Industrial Hygiene Association (AIHA) versus about 1 in 5 of the traditional stoves (Hewett et al., 2006). The clean stoves reduced the probability of overexposure by more than one-half compared to the traditional stoves. During cooking, only $1 \%$ of clean stoves could be classified as "poorly controlled" versus $40 \%$ with the traditional stoves (Hewett et al., 2006). However, there is potential for improvement in the clean stoves, especially during tasks defined as "burning".

Although mean exposures that we observed in the data were far below NIOSH's 200 ppm ceiling limit, the high variability of measurements implies a non-ignorable chance of exceeding the limit. The variability of measurements needs to be assessed to evaluate the effectiveness of clean stoves in order to improve indoor air quality.

Table 4 shows measurements of CO taken near clean and traditional stoves in a selection of other stove improvement programs. Measurement times ranged from 8 to $48 \mathrm{hrs}$. A study performed in the Santiago de Chuco province of Peru found an average reduction of $1.57 \mathrm{ppm}$ in $\mathrm{CO}$ concentrations with the use of clean stoves (Fitzgerald et al., 2012). Researchers in Guatemala found CO concentrations decreased from approximately 6 to $1 \mathrm{ppm}$ with clean stoves (Naeher et al., 2000). A study in India found stove improvements reduced CO concentrations four-fold, from approximately 8 to $1.5 \mathrm{ppm}$ (Sharma \& Jain, 2019). CO reductions reported in the literature are similar to the differences found in this study.

Figure 4 shows the risk band plot created from the Sharma and Jain (2019) CO data. The plot indicates that the probability of overexposure was about ten times as high with the traditional vs clean stoves, i.e., $5 \%$ vs $0.4 \%$.

These data support the notion that clean stoves reduce indoor $\mathrm{CO}$ concentrations and that these concentrations can reach high values although average $\mathrm{CO}$ concentrations are below existing short-term exposure limits. This study indicates that stoves are a major source of $\mathrm{CO}$ indoors because all the measurements were made when ambient outdoor concentrations of $\mathrm{CO}$ were very low.

This method has potential for rapid feedback to persons using the clean stoves. This rapid method can show the benefit of switching from traditional stoves and can help trouble-shoot if clean stoves fail to achieve the expected exposure reduction.

The major limitation of this work lies in the fact that personal exposures were not monitored. Further this study focused on only one component of the stove emissions. (e.g., analysis of PM could be done via similar technology). It is also unclear how short-term measurements may relate to more health-relevant (especially in the case of PM) long-term average exposures. Limited sample size prevented examination of the relative importance of various clean stove use procedures in reducing emissions. Also, the MSA Altair $4 X$ multigas monitor should be calibrated on site, e.g. in Peru.

This work illustrates a promising method to evaluate the effectiveness of clean stoves and supports their installation as a risk reduction measure. 
Table 4: CO concentrations associated with stoves reported in other studies.

\begin{tabular}{|c|c|c|c|c|c|c|c|c|c|c|}
\hline \multirow{2}{*}{$\begin{array}{l}\text { Author } \\
\text { (Year) }\end{array}$} & \multicolumn{3}{|c|}{ Stove } & \multirow{2}{*}{$\mathbf{N}$} & \multirow{2}{*}{$\begin{array}{l}\mathrm{N}< \\
\text { LOD }\end{array}$} & \multirow{2}{*}{$\begin{array}{c}\mathbf{A M} \\
\text { (ppm) }\end{array}$} & \multirow{2}{*}{$\begin{array}{c}\text { ASD } \\
(\mathbf{p p m})\end{array}$} & \multirow{2}{*}{$\begin{array}{c}\text { GM } \\
\text { (ppm) }\end{array}$} & \multirow{2}{*}{ GSD } & \multirow{2}{*}{$\begin{array}{c}\mathrm{T} \\
(\mathbf{h r})\end{array}$} \\
\hline & Identifier & Type & $\mathbf{K}$ & & & & & & & \\
\hline \multirow[t]{3}{*}{$\begin{array}{l}\text { Bruce et al. } \\
(2004)\end{array}$} & FIS Plancha & Clean & 46 & 46 & & 4.89 & & & & 24 \\
\hline & $\begin{array}{c}\text { Participant- } \\
\text { Purchased } \\
\text { Plancha }\end{array}$ & Clean & 16 & 16 & & 3.09 & & & & 24 \\
\hline & Open fire & Traditional & 99 & 99 & & 12.38 & & & & 24 \\
\hline \multirow{2}{*}{$\begin{array}{l}\text { Hartinger et } \\
\text { al. }(2013)\end{array}$} & $\begin{array}{l}\text { OPTIMA } \\
\text { Improved }\end{array}$ & Clean & 39 & 5760 & & 4.7 & & & & 48 \\
\hline & Open Fire & Traditional & 32 & 5760 & & 5.2 & & & & 48 \\
\hline \multirow[t]{2}{*}{$\begin{array}{l}\text { Fitzgerald et } \\
\text { al (2012) }\end{array}$} & NA & Clean & 32 & 86 & 52 & 1.57 & 2.7 & 1.1 & 2.0 & 48 \\
\hline & NA & Traditional & 32 & 86 & 28 & 3.14 & 3.8 & 2.0 & 2.5 & 48 \\
\hline \multirow[t]{4}{*}{$\begin{array}{l}\text { Naeher et al. } \\
(2000)\end{array}$} & NA & $\begin{array}{l}\text { Background } \\
\text { in home }\end{array}$ & 3 & 9 & & 0.4 & 0.3 & & & 22 \\
\hline & Plancha & Clean & 3 & 9 & & 1.3 & 0.7 & & & 22 \\
\hline & NA & Gas & 3 & 9 & & 1.3 & 0.6 & & & 22 \\
\hline & Open fire & Traditional & 3 & 9 & & 5.9 & 2.1 & & & 22 \\
\hline \multirow{2}{*}{$\begin{array}{l}\text { Sharma \& } \\
\text { Jain } \\
(2019) * *\end{array}$} & NA & Clean & 10 & 100 & 5 & 1.54 & 1.22 & 1.15 & 2.26 & 8 \\
\hline & NA & Traditional & 10 & 100 & 2 & 8.4 & 16.4 & 3.14 & 3.61 & 8 \\
\hline
\end{tabular}

Notes: K: number of stoves; N: Number of measurements; AM: Arithmetic Mean; ASD: Arithmetic Standard Deviation; GM: Geometric Mean; GSD: Geometric Standard Deviation; T: measurement duration

Figure 4. Sharma and Jain (2019) data: Risk bands for CO relative to the NIOSH $35 \mathrm{ppm} 8 \mathrm{hr}$ recommended exposures limit for different types of stoves

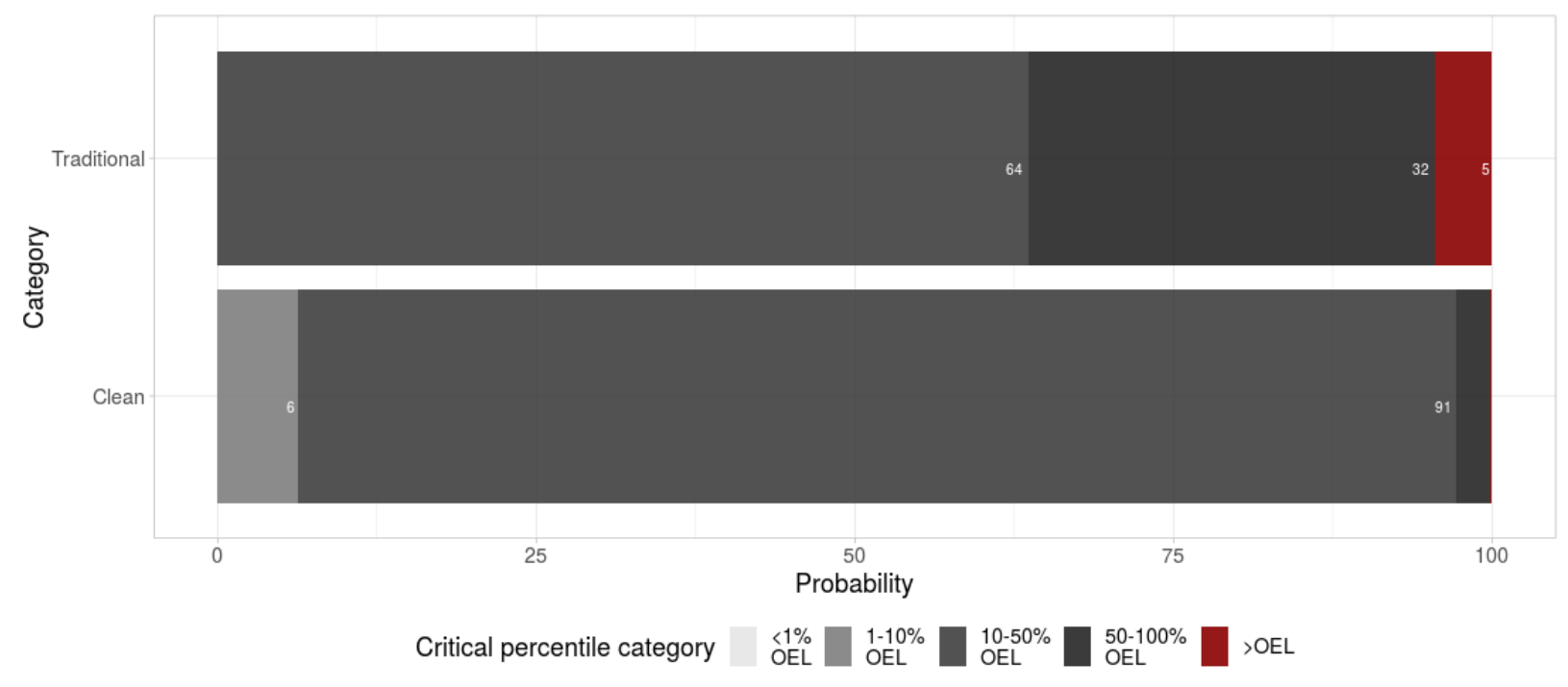




\section{References}

Bonjour Sophie, Adair-Rohani Heather, Wolf Jennyfer, Bruce Nigel G., Mehta Sumi, Prüss-Ustün Annette, Lahiff Maureen, Rehfuess Eva A., Mishra Vinod, \& Smith Kirk R. (2013). Solid Fuel Use for Household Cooking: Country and Regional Estimates for 1980-2010. Environmental Health Perspectives, 121(7), 784-790. https://doi.org/10/bs3p

Bruce, N., McCracken, J., Albalak, R., Scheid, M., Smith, K. R., Lopez, V., \& West, C. (2004). Impact of improved stoves, house construction and child location on levels of indoor air pollution exposure in young Guatemalan children. Journal of Exposure Science \& Environmental Epidemiology, 14(S1), S26S33. https://doi.org/10/bww2nf

Calzada, J., \& Sanz, A. (2018). Universal access to clean cookstoves: Evaluation of a public program in Peru. Energy Policy, 118, 559-572. https://doi.org/10/gdwk44

Central Intelligence Agency. (2019). South America Peru-The World Factbook. https://www.cia.gov/library/publications/the-world-factbook/geos/pe.html

Fitzgerald, C., Aguilar-Villalobos, M., Eppler, A. R., Dorner, S. C., Rathbun, S. L., \& Naeher, L. P. (2012). Testing the effectiveness of two improved cookstove interventions in the Santiago de Chuco Province of Peru. Science of the Total Environment, 420, 54-64. https://doi.org/10/ggdv53

Hartinger, S. M., Commodore, A. A., Hattendorf, J., Lanata, C. F., Gil, A. I., Verastegui, H., Aguilar-Villalobos, M., Mäusezahl, D., \& Naeher, L. P. (2013). Chimney stoves modestly improved Indoor Air Quality measurements compared with traditional open fire stoves: Results from a small-scale intervention study in rural Peru. Indoor Air, 23(4), 342-352. https://doi.org/10/f433nr

Hartinger, S. M., Commodore, A. A., Hattendorf, J., Lanata, C. F., Gil, A. I., Verastegui, H., Aguilar-Villalobos, M., Mäusezahl, D., \& Naeher, L. P. (2013). Chimney stoves modestly improved indoor air quality measurements compared with traditional open fire stoves: Results from a small-scale intervention study in rural Peru. Indoor Air, 23(4), 342-352. https://doi.org/10/f433nr

Hewett, P., Logan, P., Mulhausen, J., Ramachandran, G., \& Banerjee, S. (2006). Rating Exposure Control Using Bayesian Decision Analysis. Journal of Occupational and Environmental Hygiene, 3, 568-581. https://doi.org/10/b45h2x

Hornung, R. W., \& Reed, L. D. (1990). Estimation of Average Concentration in the Presence of Nondetectable Values. Applied Occupational and Environmental Hygiene, 5(1), 46-51. https://doi.org/10/bsz6td

INEI. (2007). Principales Indicadores. https://www.inei.gob.pe/

Kurmi, O. P., Semple, S., Simkhada, P., Smith, W. C. S., \& Ayres, J. G. (2010). COPD and chronic bronchitis risk of indoor air pollution from solid fuel: A systematic review and meta-analysis. Thorax, 65(3), 221228. https://doi.org/10/cb2kqn 
Lavoué, J., Joseph, L., Knott, P., Davies, H., Labrèche, F., Clerc, F., Mater, G., \& Kirkham, T. (2019). Expostats: A Bayesian Toolkit to Aid the Interpretation of Occupational Exposure Measurements. Annals of Work Exposures and Health, 63(3), 267-279. https://doi.org/10/gf9s9z

Mine Safety Appliances Company. (2017). ALTAIR 4XRMultigas Detector. https://us.msasafety.com/PortableGas-Detection/Multi-Gas/ALTAIR\%C2\%AE-4XR-Multigas-Detector/p/000080001600001026

Naeher, L. P., Leaderer, B. P., \& Smith, K. R. (2000). Particulate Matter and Carbon Monoxide in Highland Guatemala: Indoor and Outdoor Levels from Traditional and Improved Wood Stoves and Gas Stoves. Indoor Air, 10(3), 200-205. https://doi.org/10/b3nt7n

Naeher1,3*, L. P., Leaderer1, B. P., \& Smith2, K. R. (2000). Particulate Matter and Carbon Monoxide in Highland Guatemala: Indoor and Outdoor Levels from Traditional and Improved Wood Stoves and Gas Stoves. Indoor Air, 10(3), 200-205. https://doi.org/10/b3nt7n

National Institute for Occupational Safety and Health. (2007). NIOSH pocket guide to chemical hazards. U.S. Dept. of Health and Human Services, Public Health Service, Centers for Disease Control and Prevention, National Institute for Occupational Safety and Health. https://www.cdc.gov/niosh/docs/2005149/pdfs/2005-149.pdf

Pilishvili, T., Loo, J. D., Schrag, S., Stanistreet, D., Christensen, B., Yip, F., Nyagol, R., Quick, R., Sage, M., \& Bruce, N. (2016). Effectiveness of Six Improved Cookstoves in Reducing Household Air Pollution and Their Acceptability in Rural Western Kenya. PLOS ONE, 11(11), e0165529. https://doi.org/10/f9q4ff

Preller, L. (2004). Characteristics of peaks of inhalation exposure to organic solvents. Annals of Occupational Hygiene, 48(7), 643-652. https://doi.org/10.1093/annhyg/meh045

R Core Team. (2019). R: A language and environment for statistical computing. R Foundation for Statistical Computing. https://www.R-project.org/

Sharma, D., \& Jain, S. (2019). Impact of intervention of biomass cookstove technologies and kitchen characteristics on indoor air quality and human exposure in rural settings of India. Environment International, 123, 240-255. https://doi.org/10/ggnz7p

WHO (Ed.). (2006). Fuel for life: Household energy and health. World Health Organization.

Wickham, H. (2011). The Split-Apply-Combine Strategy for Data Analysis. Journal of Statistical Software, 40(1). https://doi.org/10/gddwc8

Wickham, H. (2020). plyr: Tools for Splitting, Applying and Combining Data (1.8.6) [Computer software]. https://CRAN.R-project.org/package=plyr 


\section{Appendix}

Empirical Cumulative Distribution Function Plots for LOD adjusted CO and Natural-Log Transformed LOD adjusted $\mathrm{CO}$ measurements
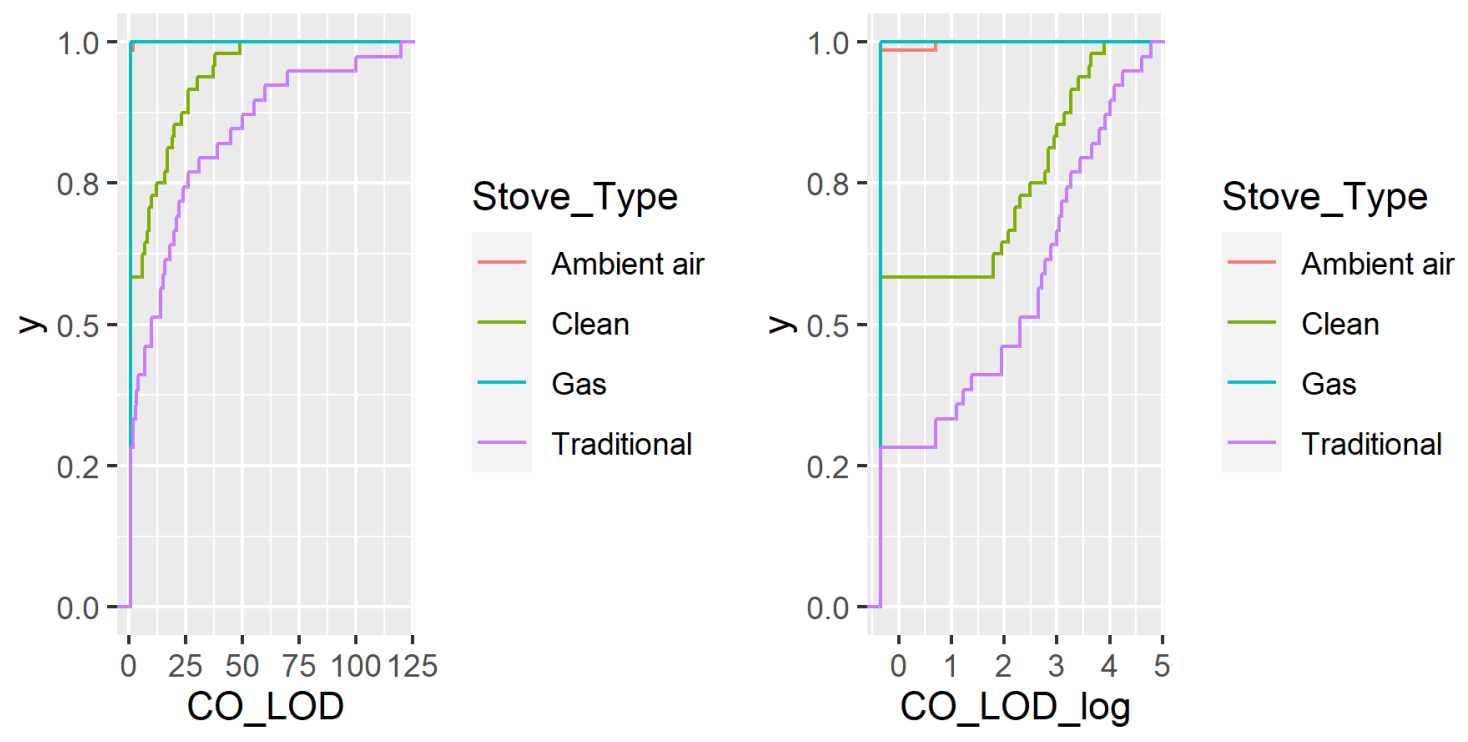